\title{
Eko-etiek en die Christen
}

P.G.W. du Plessis

Sentrum vir Geloof en Wetenskap

Potchefstroomse Universiteit vir $\mathrm{CHO}$

POTCHEFSTROOM

\begin{abstract}
Eco-ethics and the Christian

In many ways it has been stated that the root cause of our present day ecological predicament emanates from the Christian conviction that man may exploit and use nature for his own ends. This article attempts to put the accusation "that Christianity is the enemy of the environment" in the context of two main schools in environmental ethics; i.e. an anthropocentric and a milieu-centric approach. To contribute toward a Christian environmental ethics, a new task has been inferred from our critical evaluation of the accusation. Christian scholars are therefore encouraged to further a practical environmental ethos together with a biblical view of nature.
\end{abstract}

\section{Inleiding}

In die huidige ekologiese debatte word meestal moeilik versoenbare pole teenoor mekaar gestel; daarin word dilemmas geformuleer wat om oplossings roep. So word (dikwels vanuit historiese perspektief) bewaring en ontwikkeling of mens en natuur of ekologie en ekonomie of ekologie en hedonisme of ekologie en Christendom as wesenlike teenoorgesteldes geïdentifiseer (o.a. Attfield, 1983; Nash, 1991; McFague, 1991; Breuilly \& Palmer, 1992). Gewoonlik word die een pool negatief beoordeel of selfs gedemoniseer. So is dit bekend dat in bovermelde groeperinge dit eerder die "mens"-komponent of die "ekonomie"komponent of die "Christendom"-komponent is wat as probleemgeval geidentifiseer word (o.a. Roszak, 1968 en 1980; White, 1970; Machovec, 1988; Skolimowski, 1992).

Vir die doeleindes van dié artikel word die basiese klag teen die Christendom in verband met heersende ekologiese wantoestande saamgevat en daama geëvalueer. Uit die evaluering word dan 'n pertinente opdrag aan Christene in kerklike, teologiese en wetenskaplike kringe gedistilleer.

Dit word die Christendom as kultuurhistoriese krag en die Kerk as institusionele mag en die Christen wie se geloof 'n blye boodskap ook vir die aarde moet versprei, verwyt dat dit, op sy minste, afsydig staan teenoor die natuuromgewing. So het die Christendom al in die Middeleeue in Thomas Acquinas en andere se woorde 'n contemtus mundi, 'n wêreldmyding as kenmerk van goeie geloof en 
van deugsame Christenskap gepropageer. In dié verband word Franciscus van Assisi eerder as 'n uitsondering op die reël beskou - in plaas van as 'n tipering van Christelike sorg vir die natuur (o.a. White, 1970; Nash, 1991),

Verder word die aanklag gehoor dat die Christendom 'n eksklusiewe fokus plaas op die menslike drama, dit wil sê op die sonde en verlossing van die mens - in plaas van op die verval en verlossing van die hele skepping. Hierdie beklemtoning bring mee dat belangrike aspekte van die Christen se verantwoordelikheid teenoor die natuur nie in teologiese werke ondersoek of verreken is nie. In die Christelike tradisie is geen volwaardige teologie van ekologie of van die omgewing ontwikkel nie (Conradie, 1995:36, 61-65; Skolimowski, 1992:84 e.v.). Moontlik het die reformatoriese teologie se afkeer van 'n natuur-teologie ook bygedra tot die afwesigheid van 'n ekologiese teologie. Het die Reformasie dalk te eensydig klem gelê op "God's relationship to humanity" (GranbergMichaelson, 1982:3) en daarmee die aardse skepping maar eenkant toe geskuif? Hierdie tekort aan 'n natuur-etiek het selfs Albert Schweitzer al speels geformuleer toe hy gesê het: daar loop gans te min diere in ons etiek rond! (Schweitzer, 1929:26).

Toegepas op die omgewingsetiek verskerp hierdie argument soos volg: Binne reformatoriese kringe is aanvaar dat etiek in hoof- en bysaak tog handel oor die mens en dat die sedelike bestaanswyse 'n eksklusief menslike aangeleentheid is. Daar is beweer dat die Christendom 'n eksklusief mensgerigte etiek bevorder en dat die natuur en sy diere as iets sonder morele status behandel word.

Die mees fundamentele kritiek teen die Christendom is egter gerig teen die leerstuk dat die mens die sentrum van die skepping is, dat die natuur daar is vir die mens en hy daarom die natuur moet verower deur 'n leefwyse van "heers en beheers". Vanselfsprekend word die Christendom nou verantwoordelik gehou vir besoedeling, uitbuiting en vernietiging van die natuuromgewing. Binne die raamwerk van so 'n benadering word die Christendom maklik geassosieer met natuurvyandigheid (Skolimowski, 1992; Vermeersch, 1993).

Hierdie aanklag is deur Lynn White jnr. (1970) in sy beroemde/berugte artikel "The historical roots of our ecological crises" uiteengesit. Hy bevind dat die Westerse beskawing in sy huidige vorm diep beinvloed is deur Christelike waardes en aksiomas. Hy stel dat die Christendom "the most anthropocentric religion the world has seen" is (White, 1970:18-26), want dit veronderstel dat God die aarde en alles daarop ter wille van die kroon van die skepping gemaak het. "We shall continue to have a worsening ecology crisis until we reject the Christian axiom that nature has no reason for existence save to serve man" (White soos aangehaal deur Nash, 1991:70). 
Die moderne wetenskap en tegnologie funksioneer ook met die aanname dat vooruitgang gebaseer is op "the mastery and exploitation of nature" (Nash, 1991:70). Die Christendom word in wetenskaplike en tegnologiese kringe ook beskou as ' $n$ sterk aandeelhouer in die heersende mensgesentreerde benadering en uitbuitersmentaliteit teenoor die omgewing. Skolimowski (1992:87) beweer dat die Christendom (soos die Marxisme) 'n te hoè premie op die mens ten koste van die aarde geplaas het. Ook is dit 'n bekende feit dat die "environmental movement" nie 'n inisiatief uit Christelike kringe is nie (Wilkinson, 1993:17).

Vervolgens wil ek genoemde klagstaat kortliks in perspektief stel deur hoofargumente van drie hoofstrominge in die omgewingsetiek daarop te fokus. Die literatuur oor omgewingsetiek praat van 'n mensgesentreerde omgewingsetiek, 'n milieu- of natuurgesentreerde etiek en 'n omgewingsetiek van rentmeesterskap. 'n Uiteensetting daarvan is elders beredeneer (Achterberg, 1986: 196-225; Du Plessis, 1995:325-346; Barbour, 1978:366-373). Die hooftrekke van dié denkrigtings kan kortliks saamgevat word as 'n antroposentriese, 'n natuurgesentreerde en 'n Christelike omgewingsetiek.

\section{2. 'n Antroposentriese omgewingsetiek}

Die Griekse filosowe se wegbeweeg van 'n mythos-verklaring van die wereld na 'n logos-verklaring daarvan, het juis die groot verskil of kloof tussen die mens met sy logos en alle ander wesens beklemtoon. Meer nog, die implikasie van hierdie benadering was dat die mens die maat van alle dinge is. Ook gedurende die Renaissance en Verligting gaan dit daarom dat die heerskappy van die menslike gees oor die stoflike wêreld gedemonstreer word. Met Francis Bacon se bekende slagspreuk "kennis is mag!" word menslike vryheid gesien as 'n makmaak van en 'n triomf oor die natuur. Vir die Positiviste bevorder die groei van die mens se rasionele insigte in natuurprosesse juis die groei van sy mag oor die natuur. In die Verligting word wetenskap en tegnologie toegejuig as magsinstrumente in die hand van die mens sodat vooruitgang kan plaasvind. Deur planne vir groei word die omgewing gebruik en geëksploiteer ter wille van die belange van die mens en sy samelewing (Goudzwaard, 1981; Vermeersch, 1993).

In general there is agreement among Enlightenment thinkers with respect to their undaunted admiration of scientific, technical en economic progress as the bearers of the greatest benefit and utility for all of society (Goudzwaard, 1979:50).

Die magsmotief van die Verligting, soos geformuleer in die slagspreuk "kennis is mag", word in ons huidige bedeling voortgesit met reklamespreuke soos "tegniek ter wille van doeltreffendheid, welvaart en genot". Die morele kwaliteit van ons optrede word gemeet aan die nuttige effek (soveel reklametekste eindig met die selfgerigte sin: "it works for me!") en genot of plesier wat dit meebring. Waar 
nuttigheid en genot vir die mens die hoofnorm vir ons optrede teenoor die natuurwêreld geword het, daar kan ons praat van 'n utilistiese en hedonistiese moraal. Dit kan ook 'n omgewingsetiek van roofbou genoem word; dit is 'n natuuronvriendelike en mensgesentreerde etiek!

\section{3. 'n Natuurgesentreerde omgewingsetiek}

Mettertyd het die faustiese mens egter getuie daarvan geword dat sy wetenskaplik-tegniese mag met die gepaardgaande vooruitgang 'n messias met voete van klei is wat grondstowwe, energievoorrade, plant- en diersoorte laat verdwyn - selfs tot groot skade vir die mens om wie alles moet draai. Meadows se The Limits to Growth (1972) wys op die katastrofiese gevolge van ons wetenskaplik-tegnologiese mag. Verskeie skrywers wys op die negatiewe kante van 'n mensgesentreerde omgewingsetiek met sy egoïsme en paternalisme (o.a. Rozsak, 1968; Carson, 1962; Machovec, 1988). Vooruitgang word stadig maar seker deur agteruitgang ingehaal as gevolg van die besoedeling van ons leefomgewing en die vernietiging van 'n natuurlike balans tussen mens en natuur. "Oorwinning" as die botoon van eertydse publikasies oor die natuur word nou vervang met "vernietiging van die milieu" as 'n deurlopende tema (White, 1970; Leopold 1968; Schumacher, 1978). Ook die aarde is uitgeput en "smag na rus" (Conradie, 1995:15). Teenoor 'n strategie vir groei en eksploitering word tans 'n strategie vir oorlewing en vergroening uitgewerk. Verwantskap - en nie vyandskap nie - tussen mens en natuur word gesoek: “... land is to be loved and respected, is an extention of ethics ... The land ethic simply enlarges the boundaries of the community to include soils, waters, plants, and animal" (Leopold, 1968:223).

Talle pleidooie is al gelewer om die simbiose tussen mens en natuur in ag te neem (Roszak, 1980:82). Die belange van die natuur geniet voorkeur bo die belange van die mens (Skolimowski, 1992). Vanuit 'n vitalistiese en dikwels selfs ewolusionistiese benadering word "lewe" as die goue draad tussen mens en natuur beskou en word die "milieu" as die saamwoon van lewende organismes beskou (Vermeersch, 1993:67). In haar boek The Death of Nature (1985) gee Carolyn Merchant ' $n$ uiteensetting van die wyse waarop die patriargale metafoor die wetenskap sien as daardie mag wat die natuur soos 'n vrou moet onderwerp en tot onderdanige dienskneg moet intoom. Teenoor 'n aggressiewe en manlike benadering tot die natuuromgewing word die goeie gesoek in alles wat natuur-lik is (o.a. Leopold, 1968). Die aarde, die natuur word die middelpunt. In poëtiese taal stel Chief Seattle dat die aarde nie aan die mens behoort nie, maar die mens behoort aan die aarde (Seattle, aangehaal deur Achterberg, 1986:52).

Mesarovic en Pestel se beroemde tweede rapport aan die Klub van Rome wys daarop dat die ganse mensdom op 'n kruispad is en dat 'n etiese heroriëntering nodig is om die regte keuses te kan maak (Mesarovic \& Pestel, 1974). Lynn 
White (1970:24) weer glo dat ons 'n nuwe religieuse oriëntering teenoor die natuur moet vind - 'n oriëntering wat wegstuur van die antroposentriese heers- en beheersmentaliteit. Baie hedendaagse skrywers, digters, wetenskaplikes en groen aktiwiste vind inderdaad 'n alternatiewe omgewingsetiek in 'n natuursentriese of sogenaamde milieu-etiek.

\section{4. 'n Christelike omgewingsetiek}

Sommige lesers mag uit bovermelde oorsig die konklusie trek dat die Christendom (gelukkig) geen alleenreg het op die gewraakte antroposentriese benadering tot die natuur nie. Dit mag so wees; Ian Barbour (1978:367) wys ook daarop. Attfield (1983), Barbour (1978), Goudzwaard (1981), Schuurman (1988), Merchant (1985), Nash (1991) en talle teologies geskoolde skrywers lewer kritiese kommentaar op die gangbare verkeerde eksegese en die verkeerde verstaan van die sogenaamde kultuuropdrag (as die sogenaamde heers- en beheers-mentaliteit); hulle beredeneer dan dat heers en beheers nie as eksploitasie en dominansie gesien en gehanteer moet word nie, ensovoorts. James Nash (1991: 75-77) praat byvoorbeeld van 'n "serious historical oversimplification" waar die Christendom as die oorsaak van ekologiese aftakeling, kommersialisme en tegnologiese bedreiging van menslike vryheid beskuldig word. "Heerskappy oor die aarde" is ná die Bybelse opdrag aan die mens veral deur wetenskaplik-tegnologiese rewolusie verwring na 'n sogenaamde "Bybelse" sanksie om die natuur dominerend te eksploiteer.

Saam met hierdie benadering moet ons ook 'n antwoord gee op die vraag of ons as Christene akkoord gaan met die mensgesentreerde omgewingsetiek. Is ons bereid om ons in woord en daad te distansieer van die antroposentriese benadering en praktyk? "A satisfactory response to the ecological complaint against Christianity must begin with a forthright confession that at least much of the complaint is essentially true" (Nash, 1991:72).

Vir sover die Christendom die gees van eksploitasie bevorder het, moet volgens Schuurman van 'n gesekulariseerde Christendom gepraat word. Menige Christen het hom as "heer en meester" van die natuur gedra en "... de eigen waarde en zin van de natuurzijde van de schepping meer en meer uit het oog verloren" (Schuurman, 1985:34).

Insiggewend en nuttig is Wilkinson (1981) se onderskeid tussen Christianity (= Bybelse leer oor skepping en verlossing) en Christendom. Toegegee, die Christendom ( $=$ Christene in hulle daaglikse lewe en werk en denke) het hom wel skandelik skuldig gemaak aan allerlei uitbuiting en verwaarlosing van die natuuromgewing: 
Christians have interpreted the biblical teaching on human dominion over nature ... as a licence for the ruthlessly exploitative subjugation of nature. But, ... the most important exception to our agreement with those accusations of White ... is that this ruthlessness results from Christians misunderstanding and misusing Scripture, rather than the actual teaching of Scripture itself (Wilkinson, 1981:204).

Talle skrywers het reeds baanbrekerswerk verrig deur 'n Christelike benadering tot omgewingskwessies te formuleer in pleidooie vir 'n eko-etiek van rentmeesterskap: die mens is 'n rentmeester, 'n bewaarder, 'n versorger van die aarde - nie die eienaar of baas daarvan nie (o.a. Barbour, 1978; Goudzwaard, 1981; Wilkinson, 1981; Attfield, 1983; Barnette, 1972; Granberg-Michaelson, 1982; Nash, 1991; Breuilly \& Palmer, 1992; Vermeersch, 1993). Tot aan die einde van die Middeleeue was die rol van die mens verstaan as dié van "caretaker of God's creation" (Merchant, 1985:242-251).

Die Bybelse demitologisering van die natuurwêreld akkommodeer juis nie die outonomieverklaring van die mens en sy rede en sy wetenskap en tegnologie nie. 'n Bybelse Christendom lê veral groot klem op die kreatuurlike afhanklikheid van die mens: mens en natuur is naamlik op mekaar aangewys; natuurdinge is ons medekreature wat ons menslikheid of ons onmenslikheid na vore kan bring (Du Plessis, 1995:341). Ons is nie slegs vennote van die Skepper in die natuur nie; ons is ook vennote van die (Skepper se) natuur. Dieselfde natuur wie se vennoot ons mag wees, het Hy ook as 'n bondgenoot aan ons geskenk.

Ons moet die eie-waarde van die natuur erken; die natuur ontleen nie sy waardekarakter aan die mens nie; dit het 'n meer-waarde as net nuttigheidswaarde; dit het intrinsieke waarde wat die mens as geskenk, as antesedent, in sy persepsies en in sy optredes teenoor die natuur moet hanteer. Iets van die eiestandigheid van die natuur word in die verhaal van Job vertel. God gee aandag aan die natuur, selfs buite die mens om. God het hom verheug oor die goedheid van die plante, die sterre, die see en die diere - lank voor die verskyning van die mens.

Die antwoord op 'n antroposentriese omgewingsetiek is egter nie geleë in 'n natuursentriese omgewingsetiek nie. Ja, ons deel 'n organiese wêreld met plant en dier, maar ons deel veel meer met alle natuurdinge. Ons deel ook 'n morele bestaanswyse met alle natuurdinge - al is die natuur geen morele agent of morele subjek soos die mens nie. Mens en natuurdinge het 'n relatiewe eiestandigheid wat in verhouding tot mekaar na vore kom.

Ons etiek van rentmeesterskap moet die mens se verantwoordelikheid teenoor die omgewing baseer op sowel verskille as op die verbondenheid tussen mens en natuur. Die samehang en verbondenheid tussen mens en natuur beteken onder andere dat ons op analoë wyse dieselfde morele gedrag teenoor natuurdinge verskuldig is en dat ons nie sonder die natuur as etiese wesens kan funksioneer 
nie. Die mens word eties, ook via die natuur. Daar is egter soveel verskille tussen mens en natuurdinge dat die een nie in terme van die ander verklaarbaar is nie. Volgens die natuursentriese etiek word versoening tussen die belange van mens en natuur bereik deur ' $n$ reduksie van die mens na die biotiese gemeenskap. Die biotiese en die morele kan egter nie sonder meer in terme van mekaar verklaar word soos Leopold (1968:204) byvoorbeeld voorstel nie.

\section{Wel kultuurteologie, maar geen natuurteologie?}

Met hierdie retoriese vraag bedoel ek dat soos ander (Christelike) dissiplines ook die (Christelike of Bybelse) teologie nie langer kan swyg oor 'n visie en 'n aksieprogram met betrekking tot omgewingskwessies nie. Conradie (1995:89101) pleit vir 'n leefwyse wat ook rus vir die aarde inhou. Diere en die grond is ingesluit by die rusdag, die sabbatsjaar en die blye boodskap. Met 'n verwysing na Linzey beredeneer Conradie (1995:95) dit vanuit die kosmiese betekenis van die rusdag:

Die viering van die rus van die sabbat in teenwoordigheid van God is alleen moontlik as dit sáám met die (ander) diere gevier word. Dit is daarom nodig om opnuut na te dink oor die onderlinge verhouding tussen God, mense en diere. Andrew Linzey, 'n leidende figuur vanuit die Christelike tradisie in die debat oor die regte van diere, verduidelik hierdie verhouding só:

'Animals have a God-given right to be animals. The natural life of a Spirit-filled creature is a gift from God. When we take over the life of an animal to the extent of distorting its natural life for no other purpose than our own gain, we fall into sin. There is no clearer blasphemy before God than the perversion of his creatures' (Linzey, aangehaal deur Conradie, 1995:95).

Onder leiding van Calvin DeWitt (1996:38 e.v.) is 'n "report" voorgelê aan die Reformed Ecumenical Council van 1996. Die verslag sluit aan by die gedagte dat die begrip "land" 'n sentrale tema van Bybelse geloof in die Ou Testament is: "And place is where one makes vows, lives out promises, and finds covenant. ... Land as place was intimately bound to culture and shalom." In Christus bring God genesing nie net vir mense nie, maar vir die ganse skeppingsorde (DeWitt, 1996:181).

'n Onderliggende konklusie uit my betoog tot dusver is dat in reformatoriese kringe opnuut gedink moet word oor die mens se verantwoordelikheid en verhouding teenoor die natuur of leefomgewing of aardse skepping. Ons durf nie die aardse dimensie van Christus se verlossingswerk verwaarloos nie. Daarom moet ons met Loren Wilkinson (1993:20) saamstem dat verdere nadenke oor "a 
biblical cosmic Christology" nodig is: "After all, it is God's creation that is at risk - not 'nature' or 'resources' or even 'the environment'" (Wilkinson, 1993:19).

Indien met bovermelde oproep akkoord gegaan word, waar was die Christelike kerke en hulle kerkjeug en die kerklike vergaderings onlangs toe dit wêreldomgewingsdag was? In die meeste agendas en preke is die dag geïgnoreer asof omgewingsake vir buite-kerklike instansies gereserveer is. En dit terwyl onder andere soveel skeppingspsalms roep om gepreek en uitgeleef te word!

Christen-wetenskaplikes is vanuit verskillende dissiplines tog besig om te soek na 'n gemeenskaplike skeppingsverhaal tussen mens en natuur. Ek bedoel hierdie soeke in 'n enigsins ander betekenis as McFague (1991:33) se (pragtige) horisontale gemeenskaplikheid tussen mens en natuur. Op interdissiplinêre wyse moet ons ook soek na die betekenis van 'n omvattende verlossingsverhaal vir mens en natuur. Die kerk, die Christenjeug, die Christen-politikus, die gereformeerde teologie se affiniteit en sorg vir die natuur moet nie 'n vreemde toevoeging of 'n ekstra ballas wees van Christenskap in hierdie wêreld nie. Ons sorg vir en omgaan met die natuur behoort eerder deel van die blye boodskap self te wees.

Die herontdekking van die skepping as 'n fundamentele onderwerp vir Bybelse denke in aardwetenskappe, biologie, rekreasiekunde, teologie, ensovoorts sal ook die saak van Christelike wetenskapsbeoefening help bevorder. Psalm 104 vers 30 sê dat God se Gees die gesig van die aarde vernuwe. En die nuwe gelaat het juis deur en soos die opstanding van ons Here reeds deel geword van die huidige aardse geskiedenis.

Christenwetenskaplikes sal naas hulle speurtog na die aanwesigheid en die werking van God in die kultuurgeskiedenis tog ook moet werk aan 'n Bybelse perspektief oor natuurgebeure. Ook gereformeerde teoloë sal hulle onsekerheid oor 'n natuurteologie deels moet afskud en begin om 'n Bybelse skeppingslied saam te sing.

Meer nog: Christenwetenskaplikes en gereformeerde teoloè sal hulle in woord en in daad moet distansieer van 'n egosentriese omgewingsetiek en omgewingsetos. Om egter net 'n suiwer (teologiese of vakwetenskaplike of filosofiese) visie of teorie oor die natuur te ontwikkel is ook eensydig. Naas die ortodoksie sal ons juis aandag moet skenk aan die ortopraksie waar ons tans (dikwels tereg ook) die meeste kritiek moet verduur. Die geskiedenis van die Christendom se omgaan met die natuur en met die besoedelingsvraagstuk en met ekologiese kwessies tot dusver stem min mense tot dankbaarheid. Vanuit akademiese kring sal gereformeerde teoloë hulleself ook in woord en daad moet vereenselwig met 'n interdissiplinêre aanpak van Christenwetenskaplikes se studie van en sorg vir die natuur. 


\section{Literatuurlys}

ACHTERBERG, W. 1986. Partners in de natuur. Amsterdam : Uitgeverij Jan van Arkel.

ATTFIELD, R. 1983. The ethics of environmental concern. Oxford : Blackwell.

BARBOUR, I.G. 1978. Environment and man. (In Encyclopedia of bioethics. Free Press N.Y. p. 366-373.)

BARNETTE, H.H. 1972. The Church and the ecological crisis. Grand Rapids : Eerdmans.

BREUILLY, E. \& PALMER, M. 1992. Christianity and ecology. Cassell : London.

CARSON, R. 1962. Silent spring. New York : Penguin.

CONRADIE, E. 1995. Rus vir die aarde. Kaapstad : Lux Verbi.

DEWITT, Calvin B. ed. 1996. The just stewardship of land and creation. A report of the Reformed Ecumenical Council. Grand Rapids : REC

DU PLESSIS, P.G.W. 1995. Omgewingsetiek ten gunste van natuur én mens? Koers, 60(2):325-346.

GOUDZWAARD, B. 1979. Capitalism and progress. Grand Rapids : Eerdmans.

GOUDZWAARD, B. 1981. Genoodzaak goed te wesen. Kampen : Kok.

GRANBERG-MICHAELSON, W. 1982. Worldly spirituality: A call to take care of the earth. New York : Harper \& Row.

LEOPOLD, A. 1968. The land ethic. (In A sand county almanac. Oxford : Oxford University Press. p. 201-226.)

McFAGUE, S. 1991. Cosmology and Christianity. (In Daveney, S. ed. Theology at the end of modernity. Philadelphia : Trinity. p. 19-40.)

MACHOVEC, M. 1988. Die Rückkehr zur Weisheit. Stuttgart : Kreuz Verlag.

MEADOWS, D.H. e.a. 1972. The limits to growth. New York : Universe Books.

MERCHANT, M. 1985. The death of nature. San Francisco : Harper \& Row.

MESAROVIC, M. \& PESTEL, E. 1974. Mankind at the turning point. New York : Dutton.

NASH, J.A. 1991. Loving nature. Ecological integrity and Christian responsibility. Nashville \& Washington : Abingdon Press.

ROSZAK, Th. 1968. Making of a counter culture. New York : Faber.

ROSZAK, Th. 1980. Persoon en planeet. Amsterdam : Meulenhoff.

SCHUMACHER, E.F. 1978. Small is beautiful. New York : Harper.

SCHUURMAN, E. 1985. Tussen technische overmacht en menselijke onmacht. Kampen : Kok.

SCHUURMAN, E. 1988. Krisis in die landbou. 'n Reformatories-wysgerige perspektief. IRS-studiestuk no. 249. Potchefstroom : IRS

SCHWEITZER, A. 1929. Civilization and ethics. London : Black.

SKOLIMOWSKI, H. 1992. Living philosophy. Eco-philosophy as a tree of life. London : Arkana/Penguin. 
VERMEERSCH, E. 1993. De ogen van de panda; een milieufilosofisch essay. Brugge Uitgever Marc van de Wiele.

WHITE, L. 1970. The historical roots of our ecological crisis. (In De Bell, G. ed The environmental handbook. New York : Ballantine. p. 12-26.)

WILKINSON, L. ed 1981. Earth keeping. Christian stewardship of natural resources. Grand Rapids : Eerdmans.

WILKINSON, L. 1993. How Christian is the Green Agenda? Christianity Today :17-20, Jan. 